\title{
The Effect of Classroom Management Based on Cooperative Learning Approach on Science Educational Achievement Students of Elementary Sixth in the City Piranshahr
}

\author{
Mohsen Izan,,$^{1,}$ Mohammad Reza Keramati, ${ }^{2}$ and Masoud Gholamali Lavasani ${ }^{3}$ \\ ${ }^{1}$ Ph.D Student Educational Management, University of Kurdistan, Sanandaj, Iran \\ ${ }^{2}$ Associate Professor of Curriculum, University of Tehran, Tehran, Iran \\ ${ }^{3}$ Associate Professor of Educational Psychology, University of Tehran, Tehran, Iran \\ "Corresponding author: Mohsen Izan, Ph.D Student Educational Management, University of Kurdistan, Sanandaj, Iran, E-mail: mohsenizan68@gmail.com
}

Received 2015 November 11; Revised 2016 June 18; Accepted 2016 June 29.

\begin{abstract}
Background: The purpose of the present study is to investigate the effect of classroom management based on cooperative learning approach on the educational achievement of students in elementary sixth in science course.

Methods: The method of this study was quasi-experimental and with pre-test - post-test using two control groups and two experimental groups. The statistical population was elementary sixth students in Piranshahr primary schools in schooling year $2011-2012$. Sample size was 120, and through multi-stage cluster sampling, 60 students were classified into experimental groups and the other 60 students into control groups. Classroom management based on cooperative learning approach was used in the experimental groups while that based on traditional teaching approach (lecture) was used in the control groups. The study instruments were inclusive made-researcher educational achievement tests. All the tests were consistent in terms of validity and reliability coefficient (0.91). Data was analyzed by descriptive statistics (mean and standard deviation), and inferential statistics (T test).

Results: The results revealed that the educational achievement of students having classroom management based on cooperative learning approach with mean scores (15.69) were more involved in learning than students who are based on the Traditional approach (lectures) with mean scores (14.10), were learning $(\mathrm{P}<0.01)$. In the collaborative groups between the two groups, boys with the mean scores 15.63 and girls with the mean scores 15.75 were not significantly different $(\mathrm{P}<0.01)$.

Conclusions: Based on the present results, implementation of classroom management based on cooperative learning approach can have positive effects on educational achievement in Science class.
\end{abstract}

Keywords: Classroom Management Based on Cooperative Learning Approach, Educational Achievement, Science, Elementary Six

\section{Background}

Classroom as a social group and system is a place for education and training. Class groups, known as so-called communities, are secondary groups having common beliefs, norms, and values. Classroom has been the focus of educational and curriculum designers as well as educational psychologists' attention so that they would be able to create learning opportunities and facilitate teaching/learning process. Educational managers have also paid special attention to it in order to enhance the teachers' effectiveness and efficiency. Educational scholars defined classroom management as a set of skills required by teachers in order to reach an attractive, constructive, and effective educational environment.

Like other social and group situations, classroom management also requires management functions such as design, organization, leadership, supervision, control, and assessment. The classroom environment is converted into that of educational and learning as a result of the under- standing of these functions. Class situation has specific features; therefore, separation of functions is hardly impossible. However, realization of all functions in classroom management process is necessary. Classroom management has always been one of the main issues of concern for teachers because managing and controlling a classroom are bound to creating an effective learning environment in order to achieve educational objectives. Designing and organizing a classroom aid classroom management. Classroom management needs to be designed in such a way that more learning opportunities can be provided and the students' social and cooperative abilities will be enhanced. Studies on classroom design and planning indicate that lack of a well-organized curriculum causes a lot of behavioral problems among students, particularly when it is incompatible with their psychological characteristics (1).

Martin has explained the relation between education and classroom management in her study entitled "student-centered classroom management". She con- 
cluded that since education and classroom management are mutually and closely related, they should not be considered separately. This claim is based on the assumption that these two variables simultaneously influence the classroom atmosphere. However, this relation is often neglected. Although currently, new teaching methods like student-centered and cooperative approaches are constantly recommended, but traditional teaching approach is still applied in classroom environment. At the same time, it should not be forgotten that cooperative or student-centered teaching cannot be obtained without cooperative or student-centered classroom management (2). In the present study, classroom management entails all teaching-learning activities conducted in classrooms.

Scientific and educational management of teachers guides them in choosing their teaching methods, in which special attention has to be paid to the learners' conditions, situation, characteristics, level and educational facilities and equipment so that the teacher can choose suitable teaching methods and act according to the conditions and the course subject (3). Wragg, considers classroom management as planning for further involvement of the students in teaching-learning process (4).

Traditional teaching approach is the dominant approach in most class educational activities. That is, through learning process most learners do not get involved in challenging situations and are less provided with situations of cooperation, consultation, discussion, and conversation between the teacher and the students (5). In other words, in traditional classroom management, the main emphasis is placed on the text book and the teacher. Therefore, memorizing the materials (and not analysis and logical argument) is equal to learning. In such a situation, students get frustrated if they come across conceptual problems. As a result, fundamental weakness in their scientific ideology begins to get root and their academic performance will decrease (6).

Cooperative learning approach is one of the latest teaching approaches and is classified as a social cooperative one with respect to teaching paradigms. This approach can be a suitable substitution for the traditional one which is associated with several disadvantages such as rapid forgetting and students' fatigue and lack of interest (7). In order to correctly conduct this approach, it is necessary for the teachers to be familiar with its definition, nature, and learning features such as positive internal dependence, individual responsibility, progressive cooperation, interpersonal relationship, and group process since only in this case will conduction of this approach yield positive results (8). All teachers agree that cooperative learning approach affects students' educational achievement; however, there is less agreement over the effect of differ- ent styles of cooperative learning on educational achievement, which seems to be related to the quality of conducting these styles; therefore, the teacher's proficiency and knowledge are necessary in order to provide suitable conditions. In this regard, Cohen states, "The teacher's professional development is a precondition for applying cooperative approach. He should be aware of theoretical and philosophical basis of cooperative learning in order to reach a professional development in terms of conducting the approach. He should know different methods of cooperative learning and take advantage of his colleagues and other teachers' support" (9).

Learning through cooperation implies utilizing small groups in a way that students cooperate with each other in order to maximize their learning and that of other students (10).

In their study entitled, "The effect of cooperative learning on science course educational achievement and exam anxiety", Keramati et al. concluded that cooperative learning techniques can remarkably enhance the experimental students' educational achievement in science course and reduce their exam anxiety (11).

The results of a study conducted by Aziz et al., entitled, "A comparison of cooperative learning and conventional teaching on students' achievement in secondary mathematics" revealed that there was a significant difference between the experimental group and the control group after the experimental group had been taught through cooperative learning approach. These results indicated that cooperative learning group had outperformed that of the control. Therefore, cooperative learning approach can effectively improves educational achievement in students' secondary mathematics (12).

Most of the conducted studies on improving science course teaching have considered the teacher's role been vital and counted his guidance effective in formation of science concepts. However, there are very few studies on the effect of student-to-student relationship in learning science concepts. The results of the conducted studies show that students' failure in fifth and elementary sixth science courses is due to their passiveness and that one of the ways of activating them in science class is encouraging them to participate in groups in the learning process. The effectiveness of cooperative learning in educational achievement is one of the special topics of investigation in teaching and learning realm, in which less attention is paid to.

Bearing in mind the aforementioned paragraphs, the present quasi-experimental study was aimed at investigating the effects of classroom management based on cooperative learning approach on science course educational achievement of elementary sixth students in the town of Piranshahr, Iran during the school year of 2001 - 2012. 
On this basis, the following hypotheses are considered:

1. There is difference between elementary sixth student's educational achievement in science class based on classroom management and assistance approach compared to the traditional approach.

2. There is difference between elementary sixth boys and girls' student's educational achievement in science class based on classroom management based on assistance approach.

The concept of cooperative learning classroom management: Classroom is a place where a number of students sit daily and in the process of communicating with each other learn materials from their teacher. Some greenhorn teacher's worry about how they can control the class while having a good relationship with their students; this is a major problem for them. Classroom management is related to the methods and strategies whereby teachers improve students' behavior and pave the way for them to learn efficiently. Classroom management is a prerequisite for effective teaching and learning; in other words, it is the basis for a class success (13).

Effective classroom management maximizes effective teaching and learning. According to the definition provided by Wolfgang and Glickman, classroom management is all attempts made by the teacher in order to supervise class activities including social interactions and students' behavior (14). According to Wolfgang, teachers form their behavior in classroom management based on their belief regarding growth and learning. Every different behavioral pattern or style can have diverse effects on students' growth and development. Based on psychology of learning and classroom management, he has proposed a conceptual framework out of three classroom management approaches on a control continuum. These three approaches are interventionism, cooperative, and noninterventionism respectively. The more we move from interventionism approach to non-interventionism one, the less will be the class control and the more responsible and cooperative the students will be (15).

Among classroom management styles, cooperative approach based on educational psychology and theories of classroom management like Albert and Dreikurs cooperative discipline, William Glaser reality therapy without failure and Curwin and Mendler discipline with dignity, proposes methods for cooperative classroom management such as using cooperative and group techniques in learning, holding sessions to solve educational and social problems, democratically assigning class rules, and sharing responsibilities in learning and behavior and selfassessment. According to these scholars, proper application of these techniques can result in responsibility, responsibility in learning, behavioral self-control, self- positive system, self-assessment, and self-regulation (15).

In cooperative techniques, students learn through cooperation in groups and feel responsible for each other's learning. They help their classmates whenever they need so. Other's success and failure are theirs. This approach deepens learning, creativity, and innovation in students (14).

In classroom management based on cooperative approach, control and discipline are established through a cooperative process that is taking place between the teacher and the students; and students have a say in class organization and planning. The teacher provides the students with the opportunity to supervise their own performance and judge their behavior. Assessment is also carried out in a process of mutual negotiation. The advantages of such an environment include: creating an opportunity for students to have effective and constructive communication, increasing logical communication between the teacher and the students and encouraging the students to make logical arguments, and justify their beliefs and accept logical rules, accepting their responsibility in learning and class behavior, and growing in a self-positive system (14). Taking a look at investigations conducted on cooperative class management style, it can be concluded that the teacher as a manager controls the classroom in a cooperative manner. In cooperative approach, unlike traditional techniques such as memorizing and over learning, teaching and learning processes are student-centered and the teacher while keeping his managerial role in class plays a vital role in creating and managing activities and learning experiences. The teacher provides the groups with lesson subjects which they will solve and discuss and constantly supervises their activities. Students make comments about the proposed topics and while creating a faceto-face communication with their teammates, do their common assignments and help each other to obtain acceptable scores and grades. Advocates of cooperative learning approach believe that through cooperative work, students play an active role in learning process (16).

\section{Methods}

Selecting a special design is dependent on the objectives of the experiment, types of variables, and factors that limit the study in a certain context. Meanwhile in behavioral studies, selecting subjects and assigning them to groups are hardly possible and experimental and control interventions are not randomly carried out, but the design of the present study is quasi-experimental with two experimental groups and two control ones chosen from among elementary sixth students. Although subjects were randomly selected, students of both groups who had almost 
similar subjects were considered as real participants of the study. Moreover, the two groups were alike in respect with the teachers' characteristics. The independent variable of the study was the classroom management which was conducted in two cooperative learning and typical methods while the students' score of educational achievement test during a semester was the dependent variable.

In the experimental groups, the science class was held based on cooperative learning approach while the control ones was based on the typical method (lecture). The rationale behind the selection of the two experimental and control groups was to check the difficulty level of pre-and posttests and to control the cooperation of the first experimental and control groups. The statistical population of the study includes all male and female elementary sixth students of Piranshahr in the school year of 2012 - 2013.

Conducting simple sampling failed because it was impossible to create a framework for sampling out all the statistical population. In order to increase the study accuracy in experimental studies, there is an attempt to reduce the statistical population so that the interfering effect of other variables can be more accurately investigated. Therefore, multi-stage cluster sampling was conducted in order to select some schools. By so doing, the elementary schools were first divided into two groups according to the students' gender. Afterwards, a school was randomly selected from each group. Therefore, students in both groups were almost the same. Also, the two groups were similar in teacher characteristics.

Finally, two classes were randomly selected in each school. As a result, subjects of the study consisted of 4 classes (120 students), i.e. two experimental (60 students) and two control classes (60 students). The experimental group included a girl class (30 students) and a boy class (30 students) and the control group also included a girl class (30 students) and a boy class (30 students).

In the present study, two tests, a pre-test and post-test, were constructed based on the lesson contents 1 to 6 of elementary sixth science textbook in order to measure the students' educational achievement. These tests were constructed based on the related table of characteristics and according to the elementary education experts of the region utilizing the recommendations of 3 experienced elementary sixth teachers. Therefore, the tests had sufficient validity. Two parallel tests were administered on a group of elementary sixth students in another school within an interval of two weeks in order to check the reliability of the educational achievement tests. By so doing, form A was first given to the students then followed by form B. Afterwards, the correlation between the two sets of scores was calculated, in which Pearson correlation coefficient was utilized. The reliability of the tests was calculated as $91 \%$ at significance level of $\mathrm{P}<0.001(\mathrm{~N}=30, \mathrm{r}=91 \%, \mathrm{P}<0.001)$.

Data analysis was conducted through descriptive statistics (mean and standard deviation) and inferential statistics (T test) and SPSS software version 22. So that the independent t-test (Independent samples $\mathrm{T}$ test) is used to compare post-test scores between the control and experimental groups and the t-test (Paired-Samples $\mathrm{T}$ test) is used to compare mean scores of two experimental groups of boys and girls at a significance level tests ( $P$ value $<0.01$ ). Inclusion criteria included the willingness to engage in research and at least one year of teaching experience for teachers in the elementary sixth. To comply with ethical issues, efforts to confidentiality and freedom of participants to either participate in or not in the research, data confidentiality and keeping them in a secured place, and apply and study objectives were explained to the participants prior to data collection.

\section{Results}

In this section, two separate parts to the classification of the data and its analysis were discussed.

First, descriptive analysis (mean mean and standard deviation) and inferential analysis results ( $\mathrm{T}$ and T-dependent) are provided.

According to the results in Table 1, average test scores in the experimental group before executing the method of classroom management based on cooperative approach was 55.13 , then at a later time to implement this new approach, the average increased to 69.15 .

In other words, the method of classroom management based on cooperative approach on empirical science achievement of students was affected and its mean value increased.

Also, according to the $t$ test) $\operatorname{Sig}=0.000$ and $t=-9.75$ ) in Table 2, there is Significant difference confidently 0.99 between the mean scores of students in the experimental group before and after the implementation of new methods of classroom management based on cooperation approach.

According to the results presented in Table 3, mean pretest scores for the control group were administered on the basis of common practices, which are equal to 48.13, in the post test, and the average increased to 11.14.

Also, according to the test $\mathrm{t}(\mathrm{t}=-1.66$ and $\mathrm{Sig}=0.12)$ in Table 4, the average score of the control group is different in pretest and posttest, but this difference is not significant at 0.5 .

According to the results presented in Table 5, the mean scores of the experimental group in post-test after conducting classroom management based on cooperation approach is equal 15.69 and the students of the control group 
Table 1. Descriptive Statistics Comparing the Average of the Experimental Group in Pretest and Posttest

\begin{tabular}{l|c|c|c|c}
\hline Group & Variables & N. & M. & 60 \\
\multirow{2}{*}{ Experimental } & Pre-test & 1.21 & 13.55 \\
\cline { 2 - 5 } & Post-test & 60 & 13.69 \\
\hline
\end{tabular}

Table 2. Comparison of Pretest and Posttest Scores of the Experimental Group

\begin{tabular}{|c|c|c|c|c|}
\hline \multicolumn{5}{|c|}{ Pretest and Post-Test of Experimental Group } \\
\hline \multicolumn{2}{|c|}{ Difference Experimental Group in Pretest and Pos-Ttest } & \multicolumn{3}{|c|}{$\mathbf{T}$} \\
\hline M. & SD & $\mathbf{t}$ & Df & Sig \\
\hline-2.14 & 1.7 & -9.75 & 59 & $<0.000$ \\
\hline
\end{tabular}

Table 3. Descriptive Statistics Comparing Pretest and Posttest Control Group Average

\begin{tabular}{l|c|c|c}
\hline Group & Variables & N. & M. \\
\hline \multirow{2}{*}{ Control } & Pre-test & 60 & 13.48 \\
\cline { 2 - 5 } & Post-test & 60 & 1.04 \\
\hline
\end{tabular}

Table 4. Comparison of Pretest and Posttest Scores of the Control Group

\begin{tabular}{|c|c|c|c|c|}
\hline \multicolumn{5}{|c|}{ Pretest and Post-Test of Control Group } \\
\hline \multicolumn{2}{|c|}{ Difference Control Group in Pretest and Post-Test } & \multicolumn{3}{|c|}{$\mathbf{t}$} \\
\hline M. & SD & $\mathbf{t}$ & Df & Sig \\
\hline-0.41 & 1.6 & -1.66 & 59 & 0.12 \\
\hline
\end{tabular}

scores average in post-test is equal 14.10. In other words, the average students of experimental group scores in the posttest are more than the average students of control group scores.

Given that the value of F Levin at $\alpha=0.05$ was not significant, therefore, the assumption of homogeneity of variance was inferred and using independent $t$ test to examine the hypothesis with the assumption of homogeneity of variance permitted evaluation. T value in Table 6 is equivalent to -4.8 , which is significant at the level 0.01 . So we can say that the average of the control and experiment group in post-test is different and this difference was statistically significant. According to the average obtained in Table 6, we can say that the average scores of the experimental group (15.69) are more than the average scores of the control group (14.10).

Results of Table 7 show that the average scores of boy students in the experimental group is equal to 15.63 and the average scores of girl students of the experimental group is equal to 15.75 .

Given that the value of Levene's F was not at a signif- icant level $\alpha=0.05$, therefore, the assumption of homogeneity of covariance was inferred and using analysis of covariance test to examine the hypothesis with the assumption of homogeneity of covariance permitted evaluation (Table 8).

According to the data presented in Table 9, since $F$ $=1.343$ with freedom degrees of 115 and 3 is at a significant level $\alpha=0.05$, the first hypothesis of the study is rejected by the $95 \%$ certainty. In other words, by comparing the mean scores of the two boys and girls in the experimental groups (cooperative learning approach), it can be said that there was no significant difference in the classroom management style of cooperation between the average scores of students in both boys and girls groups. So the effect of classroom management style of cooperation on the progress of science learning in two groups of girls and boys are identical.

\section{Discussion}

The present study was aimed at investigating the effects of classroom management based on cooperative 
Table 5. Descriptive Statistics Comparing Experimental and Control Group Average in the Posttest

\begin{tabular}{l|c|c|c}
\hline Variable & Variable & N. & M. \\
\hline \multirow{2}{*}{ Post- test } & control & 60 & 14.10 \\
\cline { 2 - 5 } & experimental & 60 & 1.967 \\
\hline
\end{tabular}

Table 6. Results of T-Test with Two Independent Groups Experimental and Control in the Post-Test

\begin{tabular}{l|l|c|c|c}
\hline \multicolumn{1}{l|}{ Levine Test to Verify the Homogeneity of Variance Groups } & \multicolumn{3}{|c}{ t } & f \\
\hline F & Sig & t & 118 & $<0.000$ \\
\hline 1.24 & 0.267 & -4.8 & & \\
\hline
\end{tabular}

Table 7. Descriptive Statistics Comparing the Average of the Experimental Group of Boys and Girls in Post-Test

\begin{tabular}{l|c|c|c}
\hline Variable & Variable & N. & M. \\
\hline \multirow{2}{*}{ Experimental post-test } & boys & 30 & 15.63 \\
\cline { 2 - 4 } & girls & 30 & 2.5 \\
\hline
\end{tabular}

Table 8. Levene's Test Results to Check Homogeneity of Variances of Error Score for Educational Achievement in the Experimental Groups

\begin{tabular}{c|c|c|c}
\hline F & df1 & df2 & Sig. \\
\hline 0.478 & 58 & 1 & 0.511 \\
\hline
\end{tabular}

learning approach on science course educational achievement of elementary sixth students. Independent $t$ tests was used to evaluate the research hypotheses and the results of the study indicated that the experimental students who were taught through cooperative learning approach in terms of science course educational achievement outperformed the control students who were taught through the traditional approach (lecture). Weighted mean for cooperative learning classes was $\mathbf{1 5 . 6 9}$ while for the traditional classes was 14.11. This finding confirms the first hypothesis of the study, which is in agreement with the results of the studies conducted by Aziz et al. and Keramati et al. However it is not in line with the results of the studies conducted by Saeed Khan et al. (17), Hancock et al. (18) and Gharib et al. (7).

In recent years, there have been a lot of changes in the application of active and student-centered teaching/learning approaches, and development of techniques that help students create effective communication with each other has accelerated. Traditional teaching approaches in which the teacher is the only presenter of the knowledge and information and the students are inactive receivers are based on one-dimensional view of education. According to these approaches, the only role of education is to transmit knowledge to the students. In recent teaching methods in which there is emphasis on students' activeness and all-dimensional growth, the teacher is not only the transmitter of knowledge but also the facilitator of their learning process and growth of cognitive, emotional, and behavioral characteristics. Student-centered teaching can result in an increase in student's satisfaction, acceleration of learning, creation of problem solving skills, retention of learning, and establishment of critical thinking. Active learning through cooperation is an effective teaching method which in comparison to lecture method can result in higher level of learning, longer retention of the information, and students' enjoyment.

According to the results of the present study, it seems that cooperative learning can create an environment full of practice and rehearsal since the learning of science concepts requires such environment. In addition, some concepts and subjects of science require out-of-class and laboratory work, in which students can help to enhance their learning and that of others since in a cooperative group each student analyzes the subject in his/her own view which finally can make learning to be more profound and meaningful.

The results of the study also showed that there was no significant difference between the male and female experimental classes that were taught through cooperative learning approach. This result rejects the second hypothesis of the study. In other words, cooperative learning approach has similar effect on male and female students' educational achievement in science course. However, this effect is higher for female students; i.e. weighted mean 
Table 9. Covariance Analysis for the Second Hypothesis

\begin{tabular}{|c|c|c|c|c|c|}
\hline Variation Source & Sum of Squares & df & Mean of Squares & $\mathbf{F}$ & Sig. \\
\hline Pre-test effect & 45.108 & 1 & 45.108 & 187.210 & 0.000 \\
\hline The effect gender & 0.324 & 1 & 0.324 & 1.343 & 0.251 \\
\hline Error & 13.734 & 57 & 0.241 & & \\
\hline Total & 14832.750 & 60 & & & \\
\hline
\end{tabular}

for the male students was 15.63 and for the female students were 15.76. This finding is in line with the results of the studies conducted by Keramati (5). However, it is not in agreement with those of Keramati (19) that indicated female students profit more from cooperative learning approach than male students. Moreover, Khodadadnezhad (20) concluded that in cooperative learning approach male students had better performance compared to female students; however, this difference was not significant.

Previous studies have reported different results. For example, Johnson (21) have reported that male students had better performance in cooperative learning groups whereas other studies like Keramati (19), concluded that female students had outperformed the male counterpart. Conversely, studies like Webb (22) reported that the performance of male students' was totally better than that of the female students. The results of the present study also indicated that although the mean score of the female students' was higher than that of the male students, this difference was not significant, which is in line with the results of previous studies.

A brief look at the three available or dominant approaches of learning and teaching can help in drawing conclusion. One of these three approaches is the competitive approach in which students try to win. In this approach, this ideology is dominant among students that if you are the winner then I am the loser and if I am the winner, you and others are the loser. This approach creates an environment that can cause fear and anxiety among students. Even those who win are scared of losing their situation. The other approach is individual learning approach. In this approach, the students individually try to progress and their failure is of their own concern and not that of the public. In this approach, fatigue, lack of diversity, interest reduction, loneliness, and isolation are all gifts of teaching/learning process. The third approach is cooperative learning approach in which students learn in small groups. The results of hundreds of studies on this approach indicate that students in cooperative groups not only have more positive attitude but also learn and perform more effectively compared to the students of compet- itive and individual approaches.

During cooperative learning, students construct their knowledge with the help of others and connect what they learn with what they already know. They are organizing and improving their knowledge all the time and also revises and reforms it. This trend results in active, meaningful, and deeper learning (19). Like other studies, the present study also had some limitations like: Sampling method was one of the limitations of the present study, in which instead of assigning the subject into group, classes were taken as the study subjects. In other words, such sampling makes the study quasi-experimental. Control of the study remarkably increased in true experimental studies. In addition, sample size is delimited to one grade within a period of 3 months. Conducting the trial design of classroom management based on cooperative learning approach in elementary sixth was limited to only town schools and the researcher could not conduct sampling in rural regions. The experiment is not generalizable to other education levels because it has been conducted on elementary student. Due to time limitation, this approach was only applied for science course, and the result of which cannot be generalized to other courses. One of the ways to delimit this limitation is to conduct the study for a longer time for example a complete term. Due to the conduction of this method in some elementary sixth classes, increasing the number of subjects was impossible.

Since in the present study and in previous ones, the important role of cooperative learning approach in achieving educational objectives has been confirmed, the following suggestions are proposed in order to further utilize it.

1. In utilizing cooperative learning approach, teachers can help students' in all dimensional growth. In addition to deep learning of materials, students also grow in regard with their social and communication skills.

2. Holding regional conferences, effective in-service courses, and workshops can help to utilize this approach more.

3. Training teachers is the main recommendation for education authorities and managers who should inform and teach the teachers about this approach.

4. Teachers can share issues and questions that they 
encounter while utilizing this method with other teachers and find suitable solutions for them. Therefore, they will have this feeling that in addition to formal education they have received, they can also learn from their co-workers. Here, the managers' responsibility is to provide the teachers with such opportunities and support them sufficiently.

5. Prospective researchers are recommended to study the application of this approach for other courses and levels and also in other educational milieus like universities, teacher training centers, and educational groups in schools.

\section{Acknowledgments}

At the end of guidance and consultant supervisors and as well as all my colleagues in the Education of Piranshahr city acknowledgement which provided the ability to do research.

\section{Footnotes}

Authors' Contribution: In all process of the research have been used from guidance and consultant supervisors. In this way: Author Contributions: Study concept and design, Mohammad Reza Keramati and Mohsen Izan; analysis and interpretation of data, Masoud Gholamali Lavasani and Mohsen Izan; drafting of the manuscript, Izan; critical revision of the manuscript for important intellectual content, Mohammad Reza Keramati, Masoud Gholamali Lavasani and Mohsen Izan; statistical analysis, Masoud Gholamali Lavasani and Mohsen Izan.

Conflict of Interests: No declared.

\section{References}

1. Oliwa P. Supervision and guidance of learning in today's schools [In Persian]. Esfahan: Islamic Azad University; 1999.

2. Martin NK, Shoho AR, Yin Z, Kaufman AS, McLean JE. Attitudes and beliefs regarding classroom management styles: The impact of teacher preparation vs. experience. Res Schools. 2003;10(2):29-34.
3. Samadi P, Rajaeipor S, Agha Hosseini T, Ghalavand H. Explaining effective learning environment based on components of classroom management in secondary schools Urmia [In Persian]. J New Ideas Educ Faculty of Educ Psychol Zahra. 2008;4(1,2):155-76.

4. Wragg EC. An introduction to classroom observation. 2nd ed. NewYork, USA: Routledgefalmer; 1999.

5. Keramati M. Effect of collaborative learning on growth of social skills and educational achievement in math [In Persian]. J Psychol Educ Sci. 2007;37(1):39-55.

6. Korsunsky B. Ready, Set, Go: A Research-Based Approach to Problem Solving. J Educ Psychol Sci. 2004;42(8):493-7. doi:10.1119/1.1814326.

7. Gharib M, Arfanyan H, Khalkhaali H. Compare the effect two methods traditional training and collaboration on students' learning [In Persian]. J Faculty Med Tehran Univ Med Sci. 2004;62(12):1016-23.

8. Gillies RM, Ashman AF, Terwel J. New York: Springer science business Media. LLC; 2008.

9. Keramati M. Collaborative learning (learning through collaboration) [In Persian]. Mashhad: Publications fraangizesh - Ansar; 2005.

10. Barkley EF, Cross KP, Major CH. Collaborative Learning Techniques: A Handbook for college faculty. New York: Jossey-Bass; 2005.

11. Keramati M, Heidari Refhat A, Enayati Novin Far A, Hedayati A. Effect cooperative learning on the educational achievement and test anxiety in science lessons [In Persian]. 2012 ;11(44):83-98.

12. Aziz Z, Anowar Hossain M. A comparison of cooperative learning and conventional teaching on students' achievement in secondary mathematics. Procedia Soc Behav Sci. 2010;9:53-62. doi: 10.1016/j.sbspro.2010.12.115.

13. Mortazavi Zade H. Classroom management and its methods [In Persian]. J Teacher. 2008;228(19):27-30.

14. Martin NK, Yin Z, Baldwin B. Construct validation of the attitudes \& beliefs on classroom control inventory.JClassroom Interaction. 1998:6-

15. Wolfgang $\mathrm{CH}$. Solving discipline and classroom management problems. 6th ed. New York: John Wiley \& sons, INC; 2004.

16. Kuntz KJ, McLaughlin TF, Howard VF. A comparison of cooperative learning and small group individualized instruction for math in a self contained classroom for elementary students with disabilities. Educ Res Q. 2001;24(3):41.

17. Saeed Khan M, Shaukar H, Riasat A, Iqbal M, Ajoka M, Muhammad R. Effect of in quitry method on achievement to students in chemistry at secondary level. Int J Acad Res. 2011;3(1):955-1242.

18. Hancock D. Cooperative learning and peer orientation effects on motivation and achievement. JEduc Res. 2004;97(3):159-68.

19. Keramati M. The effect of cooperative learning on the educational achievement of students in physics [In Persian]. J Faculty Psychol Educ, Tehran University. 2008;28(2):147-65.

20. Khodadadnejad A. Effect collaborative teaching on attitudes and math educational achievement in fifth grade students [In Persian].J New Ideas Educ Sci. 2009;5(1):73-93.

21. Johnson D, Johnson R. Learning together and learning alone. New York: Prentice Hall; 1987.

22. Webb NM. Peer interaction and learning in small groups. Int JEduc Res 1989;13(1):21-39. doi: 10.1016/0883-0355(89)90014-1. 